\title{
Extracellular Proteolysis in Transgenic Mouse Models of Breast Cancer
}

\author{
Kasper Almholt • Kirsty Anne Green • \\ Anna Juncker-Jensen • Boye Schnack Nielsen • \\ Leif Røge Lund • John Rømer
}

Published online: 8 February 2007

(C) Springer Science + Business Media, LLC 2007

\begin{abstract}
Growth and invasion of breast cancer require extracellular proteolysis in order to physically restructure the tissue microenvironment of the mammary gland. This pathological tissue remodeling process depends on a collaboration of epithelial and stromal cells. In fact, the majority of extracellular proteases are provided by stromal cells rather than cancer cells. This distinct expression pattern is seen in human breast cancers and also in transgenic mouse models of breast cancer. The similar expression patterns suggest that transgenic mouse models are ideally suited to study the role of extracellular proteases in cancer progression. Here we give a status report on protease intervention studies in transgenic models. These studies demonstrate that proteases are involved in all stages of breast cancer progression from carcinogenesis to metastasis. Transgenic models are now beginning to provide vital mechanistic insight that will allow us to combat breast cancer invasion and metastasis with new protease-targeted drugs.
\end{abstract}

MMTV

mouse mammary tumor

Keywords Plasminogen - Urokinase uPA · uPAR ·

Fibrinolysis · Matrix metalloprotease MMP. DCIS

$\begin{array}{ll}\text { Abbreviations } \\ \text { CIS } & \text { carcinoma in situ } \\ \text { DCIS } & \text { ductal CIS } \\ \text { DMBA } & \text { 7,12-dimethylbenzanthracene } \\ \text { ECM } & \text { extracellular matrix } \\ \text { MMP } & \text { matrix metalloprotease }\end{array}$

K. Almholt $(\bowtie) \cdot$ K. A. Green · A. Juncker-Jensen •

B. S. Nielsen $\cdot$ L. R. Lund $\cdot$ J. Rømer

Finsen Laboratory,

Rigshospitalet 3735, Copenhagen BioCenter, Ole Maaløes Vej 5,

DK-2200 Copenhagen, Denmark

e-mail: kasper@finsenlab.dk

\section{Introduction}

Breast cancer progression is accompanied by increased expression of proteases that are capable of degrading the 
extracellular matrix (ECM) leading to cancer cell invasion and eventually to dissemination of cancer cells to other organs. The proteolytic capability of breast cancers is reminiscent of the inherent proteolytic capability of the healthy mammary gland. Extracellular proteases are necessary for the dynamic tissue remodeling that takes place during normal mammary gland development and pregnancy cycling (reviewed in [1]). During development, the invasive phenotype of terminal end buds is associated with a controlled proteolytic digestion of ECM in the fat pad, and side branching of the newly formed ducts requires a focal degradation of basement membrane. The proliferative response of the epithelium during pregnancy and lactation is accompanied by limited proteolytic activity. In contrast, the involution of the lactating gland to a resting gland after weaning restructures the entire gland and requires extensive degradation of ECM and basement membranes. Extracellular proteases are thus more abundant during involution than at any other stage during development and the pregnancy cycle. The similarity between the proteolytic repertoire of the normal gland and the proteolytic capability of mammary cancers is best illustrated by the fact that the cellular expression patterns of individual proteolytic components are very alike, especially when comparing involution and cancer [2]. In terms of extracellular proteolysis, breast cancer in many ways resembles a mammary gland in a state of continuous and uncontrolled tissue remodeling.

\section{Matrix Metalloproteases and Plasminogen Activators}

Two families of extracellular proteases have been extensively studied in relation to mammary gland morphogenesis and cancer. These are the matrix metalloproteases (MMPs) and the group of serine proteases that govern the activation of plasminogen $(\mathrm{Plg})$. Figure 1 illustrates the connected extracellular proteolytic network of the MMPs and the Plg activation system (PA system).

The liver-derived proenzyme Plg is found in high concentration throughout the body. In contrast, expression of the specific urokinase- and tissue-type Plg activators (uPA and tPA) is induced locally and thus determines where and when Plg is converted to the active protease plasmin [3, 4]. Plasmin, activated by uPA, is important for a number of tissue remodeling processes that, in addition to pregnancy cycling of the mammary gland [5], include wound healing [6] and embryo implantation [7]. In contrast, tPA is acknowledged to be primarily involved in thrombolysis and neurobiology [3,4] but is also active during wound healing [8]. A newly identified Plg activator, plasma kallikrein (pKal), is involved in adipocyte differentiation in the involuting mammary gland [9] and in wound healing [8].
The MMPs constitute a large family of 22 extracellular metalloproteinases in mice (24 in humans) $[10,11]$ (an updated list of human and mouse proteases is available at http://web.uniovi.es/degradome/). MMPs are essential for a number of physiological tissue remodeling processes during ontogenesis and adult life, including mammary gland development [12, 13], bone development [14], wound healing [15], and embryo implantation [7]. During mammary gland development MMP-2 is involved in ductal elongation, and MMPs-2 and -3 are involved in ductal branching [13]. MMP-3 is also rate limiting for adipocyte differentiation during post-lactational involution [16]. The ductal tree is eventually fully formed in mice that are deficient in MMP-2, -3 or several other MMPs, indicating that the remaining MMPs are able to replace their activity in a functional overlap.

Several members of the MMP and PA systems are involved in breast cancer progression. We will focus on the role played by these extracellular protease families during the various stages of breast cancer progression, from the initial hyperplastic lesion to disseminated disease, with particular emphasis on the insight gained from transgenic mouse models.

\section{Mouse Models of Breast Cancer}

The mouse mammary gland is ideally suited to study cancer progression for a number of reasons. First of all, there are many similarities between the human and mouse mammary glands (for detailed reviews see [17, 18]). Human and mouse mammary glands contain the same epithelial cell types: the ductal epithelial cells, luminal (milk secreting) epithelial cells, and the myoepithelial cells. They also contain adipose tissue and stroma, although the composition of the stroma differs between the human and mouse glands. One of the few differences between the species is that the epithelium in the mouse gland is surrounded by adipose tissue and a relatively sparse stroma, whereas the human mammary epithelium is encompassed by a specialized fibroblastoid stroma and is not in direct contact with adipocytes. The epithelial structure in the mature nulliparous mouse gland is also much less developed compared to the human gland and consists only of a branching but otherwise naked ductal tree. In contrast, the mature ductal tree in non-pregnant women contains groups of acini at the end of terminal ducts, named terminal ductal lobular units (TDLU). The mouse epithelium develops similar lobuloalveolar structures transiently during the estrus cycle in certain mouse strains [19] and always during early pregnancy, and in this way the resting human gland is structurally more similar to the pregnant mouse gland. In 


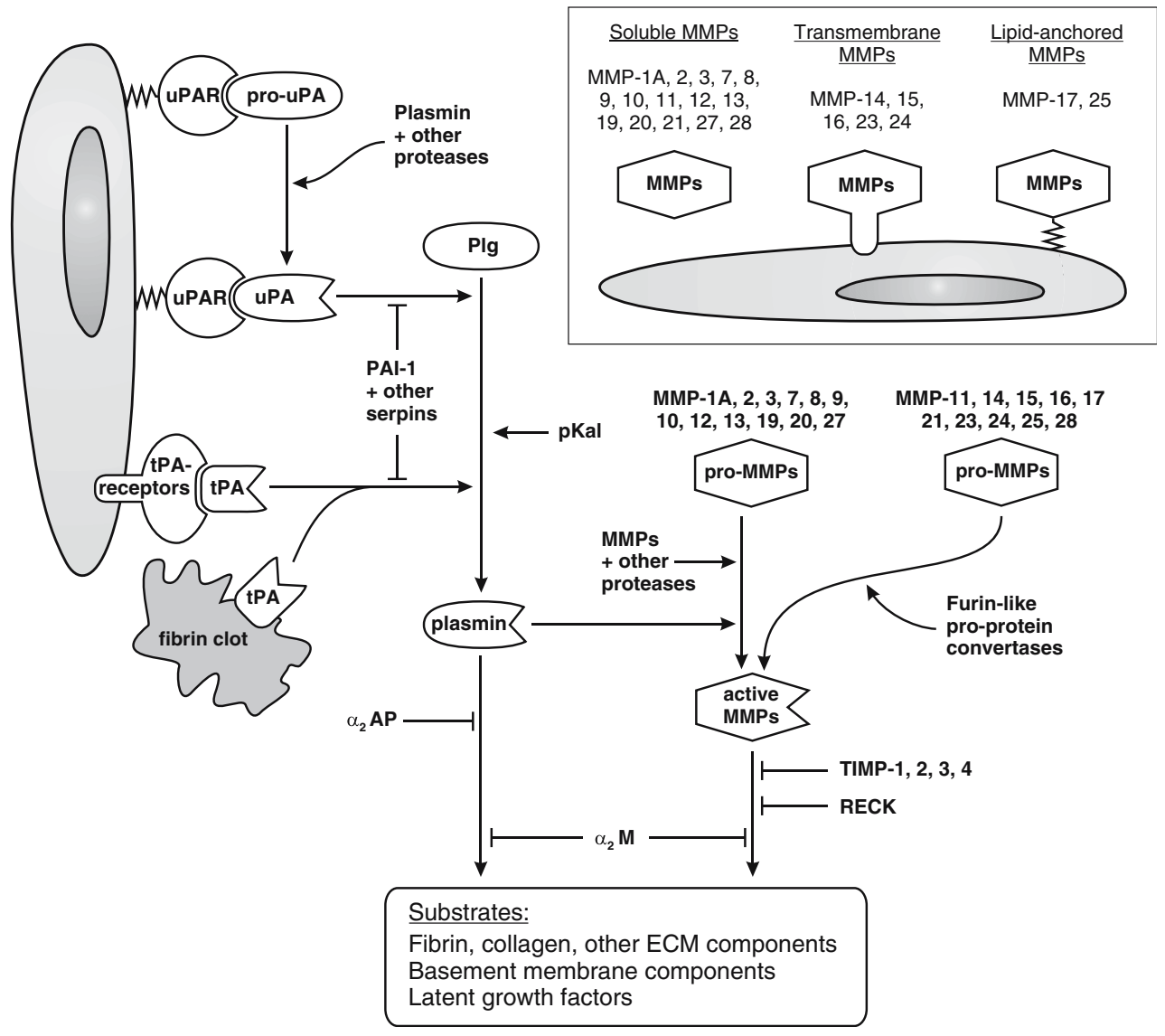

Figure 1 The PA and MMP systems in the mouse. Plasmin and MMPs are two major sources of extracellular proteolysis. Plg is converted to the active protease plasmin by one of three Plg activators, $\mathrm{uPA}, \mathrm{tPA}$, and pKal. The generation of plasmin is enhanced by the binding of uPA to the cell surface receptor uPAR, and by the binding of tPA to coagulated fibrin or to cell surface proteins (annexin II [86] and CKAP4 [87]). The conversion of pro-uPA to active uPA may be initiated by several proteases, depending on the tissue in question. Additional pro-uPA is then activated by plasmin in a positive feedback loop. The PA system is tightly controlled by several serine protease inhibitors (serpins); the primary and most specific inhibitors are the Plg activator inhibitor PAI-1 that targets uPA and IPA, and the plasmin inhibitor $\alpha_{2}$-antiplasmin $\left(\alpha_{2} \mathrm{AP}\right)$. Major substrates of plasmin include fibrin, fibronectin, laminin, and other ECM proteins, latent TGF- $\beta$ and other growth factors, and pro-MMPs. The 22 different mouse MMPs are all extracellular, and are either soluble or membrane-anchored. Like the serine proteases of the PA system, the

some transgenic breast cancer models, the earliest hyperplastic lesions may also resemble TDLU-like structures [20].

A second ideal feature of the mouse mammary gland is that it is readily accessible for monitoring tumor growth and for other experimental procedures. This has lead to the development of numerous transplanted models, chemically induced models and transgenic models. We will limit our discussion to the transgenic and chemically induced models since there are inherent problems of transplanted models that may introduce bias. Depending on the study design,
MMPs are also synthesized as inactive proforms that require proteolytic activation. Ten of the 22 pro-MMPs, including the membrane-anchored MMPs, have a furin cleavage site and may be activated by furin-like proprotein convertases before they are secreted. The remaining pro-MMPs are activated extracellularly, typically by plasmin or by other MMPs. The MMP system is counterbalanced by a group of four inhibitors, TIMPs, that have varying specificities for individual MMPs. In addition, the membrane-anchored MMP inhibitor RECK regulates a subgroup of MMPs including MMPs-2, -9 , and -14 [88]. An excess of plasmin or MMP activity may ultimately be cleared by $\alpha_{2}$-macroglobulin $\left(\alpha_{2} \mathrm{M}\right)$ which is a non-specific protease scavenger. The MMPs are collectively able to degrade any component of the ECM. Important substrates for the MMPs as a group include the native fibrillar collagens and all four major components of the basement membrane: collagen type IV, laminin, nidogen/entactin, and heparan sulfate proteoglycans.

these obstacles can include: (1) a species barrier between proteolytic components supplied by the transplant and the host (as documented for human and mouse uPA and its receptor UPAR [21]); and (2) a cellular inconsistency with respect to protease expression in the sense that the majority of proteolytic components are supplied by stromal cells in human breast cancers while epithelial-based cancer cell lines often express the very same proteolytic components [22]. This is presumably due to genetic alterations that have occurred during in vitro culture. Furthermore, (3) when 


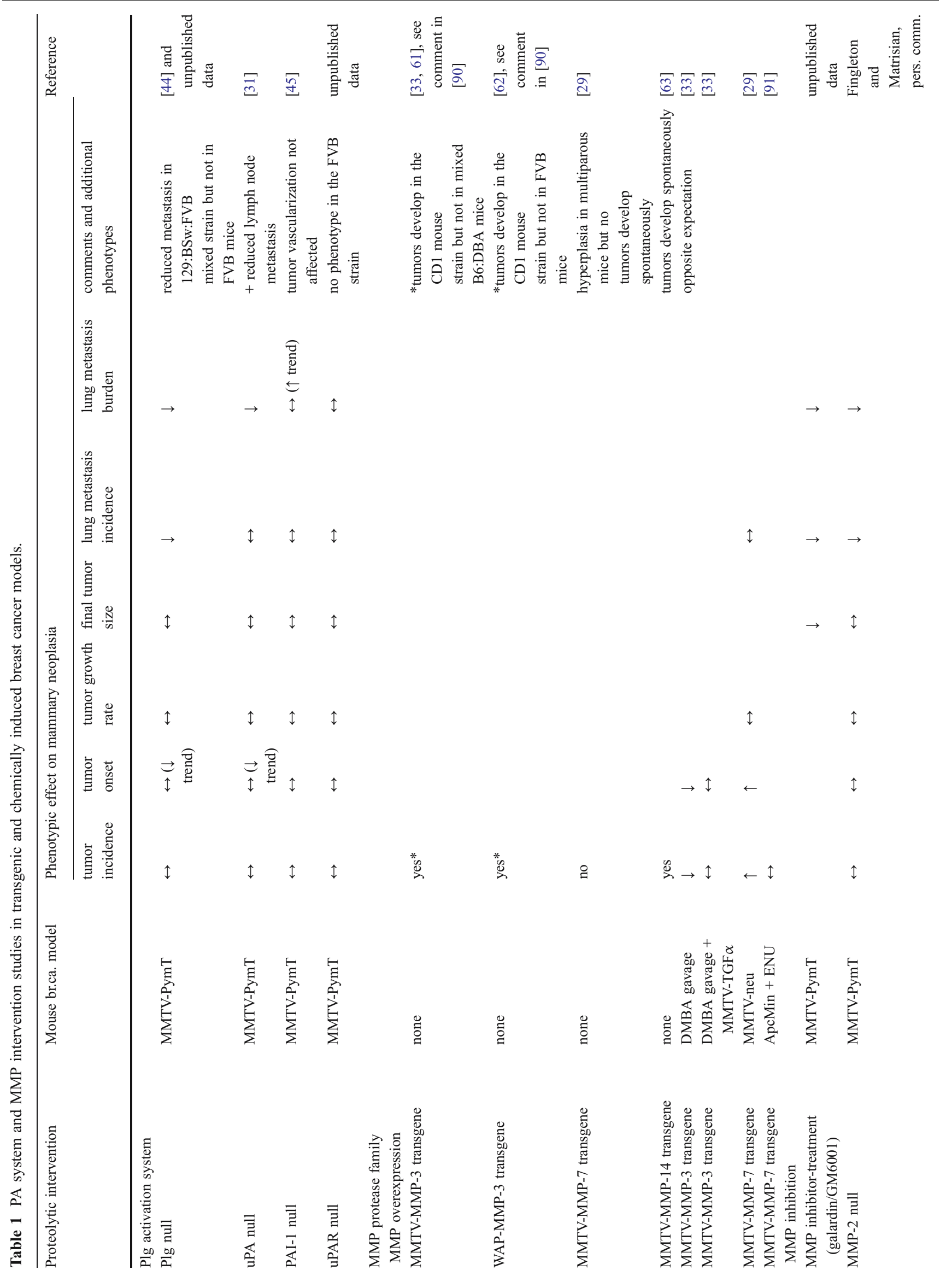




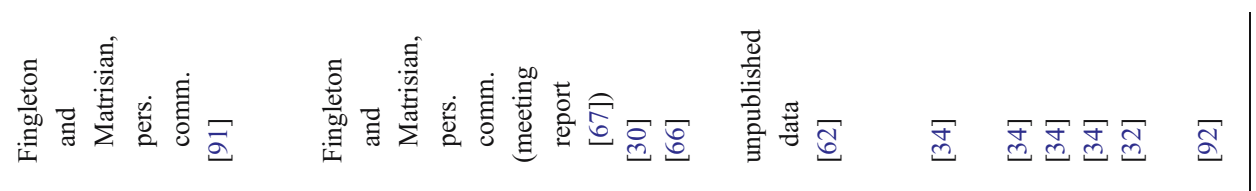




$\uparrow$

$\uparrow$

$\uparrow$

$\uparrow$

$\leftarrow \quad \uparrow$

$\rightarrow \rightarrow \uparrow$

$\uparrow$

$\uparrow \quad \uparrow$

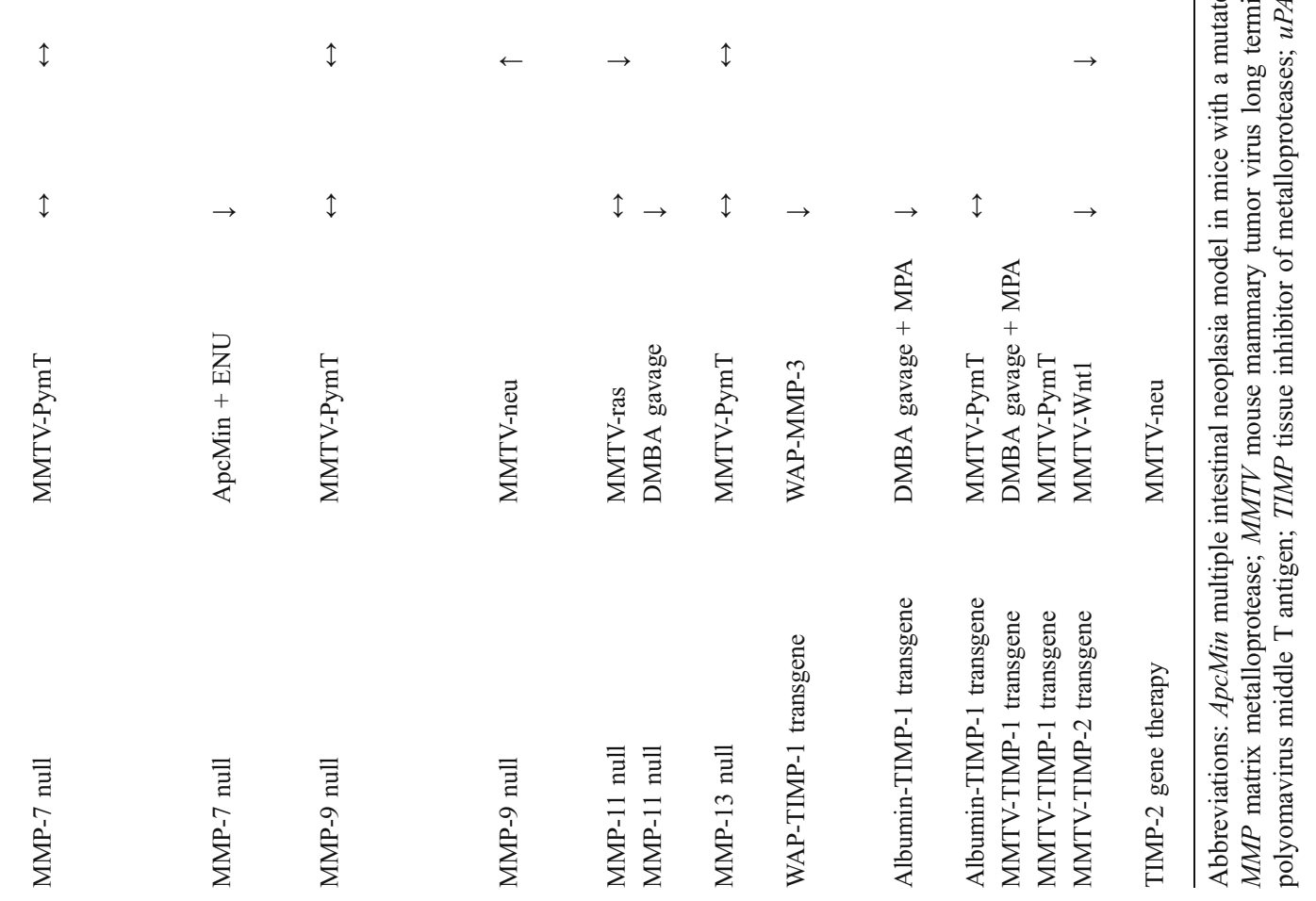

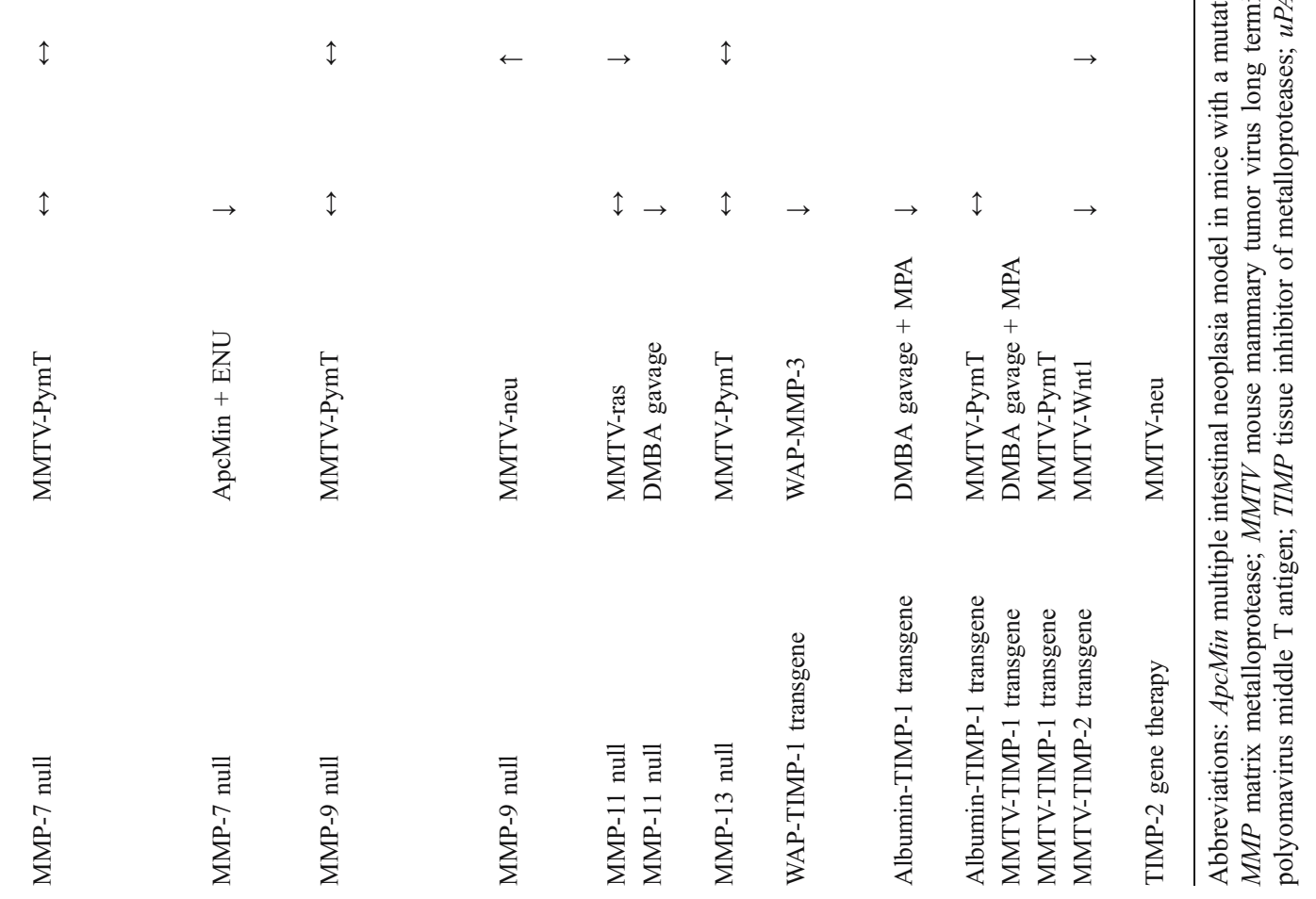

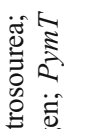

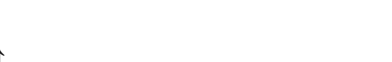

$\uparrow$

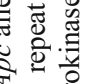

$\rightarrow \quad \quad \quad \begin{aligned} & 0 \\ & 0\end{aligned}$ 
gene-deficient mice are used as hosts for syngeneic transplantation, it is possible that a tumor-suppressive phenotype in the protease-deficient host is due to an immune response directed at the protease-producing transplant.

A third advantage of the mammary gland for cancer research is that there are more transgenic models of mammary cancer than for any other cancer form, primarily because relatively specific promoters are available for targeting oncogene expression to the mammary epithelium. The promoters most frequently used stem from the whey acidic protein (WAP) gene, and the mouse mammary tumor virus long terminal repeat (MMTV). The promoters are not equally active at all stages of mammary gland development and the pregnancy cycle [23]. The MMTV promoter is active during puberty but is greatly enhanced during pregnancy. The WAP promoter is primarily active from mid pregnancy and during lactation. Accordingly, cancer progression is accelerated by pregnancies in most transgenic models and some models only develop tumors after a number of pregnancies.

Finally, the tumor histopathology of several transgenic models is very similar to human breast cancers [17]. The histopathology seen in a single mouse model is, however, relatively uniform and often characteristic of the inducing oncogene, and in this way no single model replicates the variability of tumor phenotypes seen among different breast cancer patients $[17,24]$. This drawback is to be expected, considering the fact that transgenic models rely on a welldefined initiating oncogene in mice with a homogenous genetic background (inbred strains). In contrast, human breast cancers arise from combinations of multiple mutations in women with heterogenous genetic backgrounds. A notable similarity between mouse and human tumors is the development of a reactive stroma and the appearance of extracellular proteolysis in the tumor microenvironment. There are, however, also significant drawbacks to the use of transgenic models, such as the fact that they express oncogenes in the entire mammary epithelium (or at least a large part of it) often giving rise to multiple tumors and in some models a general hyperplasia of the entire gland. By contrast, human tumors derive from a single site, therefore resulting in a single tumor in the breast.

A comprehensive list of transgenic breast cancer models is available at http://emice.nci.nih.gov/ and has recently been reviewed [23]. Here we will focus on models that have been studied in relation to extracellular proteolysis. Table 1 summarizes the studies that describe MMP or PA system intervention in transgenic and chemically induced breast cancer models. It is evident from Table 1 that the role of proteases has almost exclusively been studied in models, in which one of the four oncoproteins ErbB-2 (neu) [25], Ras [26], Wnt1 [27], or the polyomavirus middle T antigen (PymT) [28] are induced by the MMTV promoter. ErbB-2 is often overexpressed in human breast cancers. Ras and the downstream effector proteins of Wnt1 and PymT are also frequently activated in human breast cancer, although mutation/overexpression of Ras and Wnt1 are infrequent in breast cancer and there is no cellular counterpart of the PymT oncogene [23]. In all four transgenic models, tumor incidence is $100 \%$ or at least approaches $100 \%$ depending on the time allowed for observation [29-32]. Tumor incidence has only in a few cases $[29,32]$ been affected in protease intervention studies (Table 1). Tumor onset in the ErbB-2, Ras, and Wnt1 models can be accelerated by multiple pregnancies $[25,30,32]$ and mice used for experiments are frequently mated continuously, at least in the Ras and Wnt1 models [30, 32]. The PymT model is exceptionally fast even in non-pregnant mice, where the average tumor latency is approximately 1.5 months [31] compared to $4-7$ months for multiparous mice in the three other models [25, 30, 32]. In all four models the tumors metastasize primarily to the lungs although the models differ in aggressiveness. The PymT model is the most aggressive and the Wnt1 model the least aggressive [31,32]. A notable exception to the use of transgenic models in protease studies is the chemically induced mammary tumors that are induced by orally administered 7,12-dimethylbenzanthracene (DMBA) with or without hormone supplementation [33, 34]. The DMBA model is primarily a carcinogenesis model, since the tumors generally do not progress to form metastases [33, 34].

A feature of any transgenic model that is particularly relevant to extracellular proteolysis is the transition from pre-invasive (carcinoma in situ, CIS) to invasive breast carcinoma. Most human pre-invasive lesions are ductal CIS (DCIS), and in these lesions the carcinoma cells accumulate in the ducts confined by the myoepithelial cell layer and the basement membrane. Proteolytic degradation of the basement membrane leads to depolarization of the myoepithelial cells and offers the carcinoma cells access to the surrounding periductal stroma $[35,36]$. In some human breast carcinomas the tumor suppressive myoepithelium surrounding an emerging tumor can persist for a relatively long period of time. In the MMTV-PymT model the late stage tumors resemble human invasive ductal breast cancer, but the myoepithelium is lost very early in tumor progression and it is therefore a poor model of the CIS stage ([20] and unpublished data). The lack of an intact myoepithelium, as seen in the MMTV-PymT model, does not necessarily make the neoplastic cells invasive. These lesions fall in the broad category of mammary intraepithelial neoplasia (MIN), which includes CIS-like lesions but is used more generally in mouse tumors to describe pre-malignant epithelial cells that have significant nuclear atypia and are surrounded by an intact basement membrane [37]. A few transgenic breast cancer models have been described to develop CIS lesions with morphologic similarities to human DCIS and later 
progress into invasive breast cancer. These include the $\mathrm{C} 3$ (1)-SV40-T prostate cancer model that also develops mammary lesions [38], the WAP-SV40-T model [39], and the MMTV-neu models [17]. However, the CIS stage has not been the focus of protease intervention studies so far.

\section{Protease Expression in Transgenic Breast Cancer Models}

Extracellular proteases are generally absent in resting mammary glands but are present as the gland undergoes the pregnancy cycle. The levels of a number of extracellular proteolytic components are particularly upregulated during post-lactational mammary gland involution. These include uPA, tPA, MMPs-2, -3, -9, -11, and their corresponding inhibitors PAI-1 and TIMP-1 [5, 40-42]. The upregulated proteases and protease inhibitors are presumably required for the orderly restructuring of the lactating gland to a virgin-like state (discussed later). During breast cancer development, a similar proteolytic program is activated in the diseased gland and extracellular proteases are abundant in invasive breast cancers of both humans and mice. Figure 2 gives a schematic comparison of the expression patterns of MMP and PA system components in human breast cancer and in the MMTV-PymT transgenic breast cancer model, which has been used to analyze the expression of several extracellular proteases. One study used laser microdissection to isolate cancer cells and stromal cells followed by quantitative RT-PCR to examine the expression level of MMPs and the PA system [43]. The study concluded that stromal tissue adjacent to cancer cells expresses higher levels of uPA, PAI-1 and MMPs-2, $-3,-11$, -13 , and -14 than the cancer tissue. The predominantly stromal expression patterns of all these components in the MMTV-PymT model has been confirmed by in situ hybridization [31, 43-46]. Using immunohistochemistry, UPAR expression was found primarily in fibroblasts, endothelial cells, and in some macrophages in the MMTV-PymT model (unpublished data). In situ hybridization was used in another study on MMTV-PymT tumors to determine the expression pattern of four of the membranetype MMPs: the transmembrane MMPs-14, -15 , and -16 and the GPI-linked MMP-17 [46]. MMPs-14 and -16 were detected in the stroma whereas MMP-15 was the only protease found predominantly in the epithelium. MMP-17 expression was not observed in the MMTV-PymT tumors. The majority of these findings reflect the mRNA expression data for human breast cancer, since uPA [47], PAI-1 [48], and MMPs-2 [49], -3 [50], -11 [49], -13 [35], and -14 [51] all are found predominantly in the stroma (see suppl. data to review by Egeblad and Werb 2002 [10]). Immunoreactivity for UPAR is also primarily found in the stroma [52].
Figure 3 provides two examples of this close correlation between human and transgenic mouse tumors: MMP-13 is focally expressed in stromal cells in patient material [35] and in MMTV-PymT transgenic tumors [43] (Fig. 3c-d). Similarly, the primary uPA inhibitor PAI-1 is expressed in stromal cells in MMTV-PymT mice [45] and in breast cancer patients [48] (Fig. 3e-f). The PAI-1-producing stromal cells were identified as myofibroblasts in the human samples. It is of note that this cell type is uncommon in the normal mouse and human glands but is abundant in tumors from both transgenic mice (unpublished data) and breast cancers patients [53].

Recently, the MMTV-Wnt1 model has also been used to study the expression levels of a number of MMPs during mammary tumor formation by RT-PCR and in situ hybridization [32]. MMPs-2, $-3,-9,-13$, and -14 displayed increased expression levels in hyperplastic glands and mammary tumors. MMPs-2, -3 , and -9 were exclusively expressed in the stroma, while MMPs-13 and -14 were found predominantly in the cancer cells and to a lesser extent also in stromal cells. Again, most of these MMPs have been reported with similar expression patterns in human breast cancer, although MMPs-13 and -14 are predominantly stromal in ductal breast cancer $[35,51]$. It is noteworthy that the MMTV-PymT and MMTV-Wnt1 models have broadly similar but not identical localization and expression of MMPs.

The initial expression of proteases in human breast cancer may be associated with the transition from DCIS to invasive ductal carcinoma. The transition to invasive cancer can be identified histopathologically in some DCIS lesions, particularly facilitated by immunohistochemical staining of myoepithelial cells and intraductal neoplastic cells. Expression studies of MMPs in human DCIS material have shown that MMP-13 is focally upregulated in microinvasive foci (Fig. 3b) in contrast to MMPs-2, -11, and -14, which are all more broadly expressed in the samples [35]. All four of these MMPs are expressed in periductal (myo)fibroblasts, indicating an intense stromal involvement during early invasion. Brummer et al. found that TIMP-1 is also upregulated in areas of early invasion [54]. Mimicking the human situation, the C3(1)-SV40-T model develops DCISlike lesions, in which MMP-13 is upregulated specifically in those DCIS-like structures that show signs of invasion (Fig. 3a). In human samples, uPA and uPAR are also focally upregulated in areas of microinvasion together with MMP-13, suggesting that plasmin-directed proteolysis coincides with MMP activity in the transition to invasive cancer [36].

Thus, the extracellular proteases expressed in transgenic breast cancer models generally mirror those identified in human breast cancer both in terms of expression and localization. These findings suggest that transgenic models 


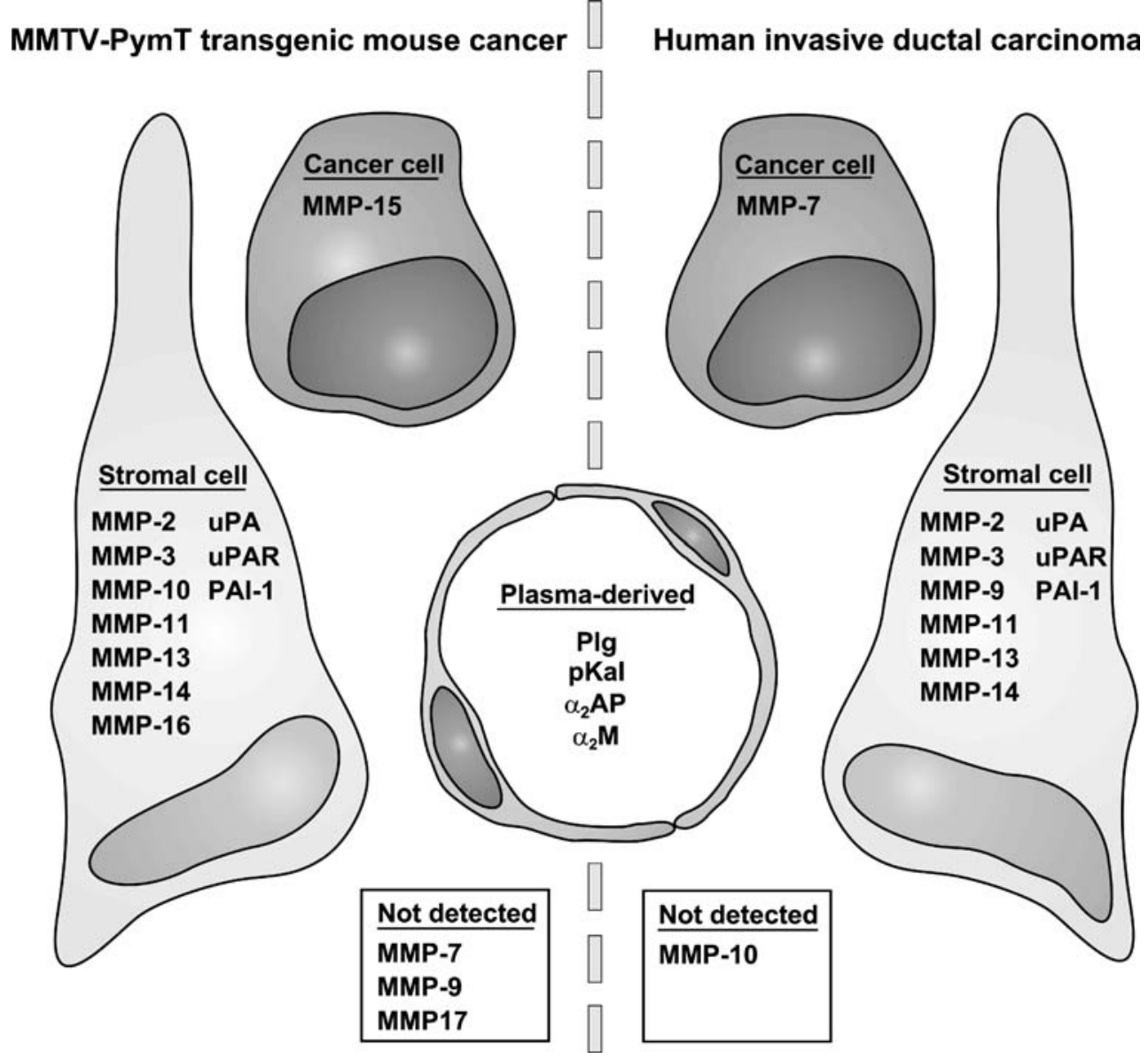

Figure 2 Expression of MMPs and PA components in breast tumors in humans and in MMTV-PymT transgenic mice. MMPs and PA components are expressed by cancer cells or stromal cells in breast tumors or are present as ubiquitous plasma-derived proteins. The predominant source of each mRNA/protein is illustrated for human ductal breast cancer and for the MMTV-PymT model in mice. Only those proteases and related components that have been analyzed in the MMTV-PymT model are included in the comparison. Only mRNA analyses are included except for uPAR, which was analyzed by

are useful tools for the study of protease involvement in breast cancer invasion and metastasis.

\section{Functional Studies of Proteases in Breast Cancer Progression}

Proteases in Post-lactational Mammary Gland Involution

Mammary gland involution following weaning can to some extent be regarded as a surrogate model for the role of proteases in breast cancer invasion due to the extensive tissue remodeling and extracellular proteolysis taking place. The first, reversible stage of involution is prematurely activated in Plg-deficient mice likely due to increased milk stasis during lactation [55]. However, the second, protease-

immunohistochemistry in both species. The "Not detected" category includes proteases that were sporadically expressed in the tumors. The data for the MMTV-PymT model: uPA [31]; PAI-1 [45]; uPAR, MMPs-7, -9, -10 (unpublished data); MMPs-2, -3, -11, -13, -14, uPA, PAI-1 [43]; MMPs-14, -15, -16, -17 [46]. The data for invasive ductal breast cancer: uPA [47]; PAI-1 [48]; uPAR [52]; MMP-2 [49]; MMP-3 [50], MMP-7 [89]; MMP-9 [72]; MMP-10 [89]; MMP-11 [49]; MMP13 [35]; MMP-14 [51].

dependent and irreversible stage of involution seems to be delayed in Plg-deficient mice [5]. Involution is eventually accomplished in Plg-deficient mice probably due to compensating action of other proteases including MMPs. In support of this hypothesis, implantation of TIMP-1 slow release pellets into involuting mammary glands delays alveolar regression [40], and likewise TIMP-3 null mice exhibit accelerated involution [56]. In contrast, transgenic overexpression of TIMP-1 in luminal cells did not provoke an involution phenotype [16, 57], which may be a cell-oforigin effect since endogenous TIMP-1 is produced by stromal cells during involution [40, 58]. Similarly, the accelerated involution observed in mice that overexpress MMP-3 in luminal cells [57, 59] could be an effect of overexpressing a stromal protein in luminal cells, and is not supported by evidence from MMP-3 null mice that do not 
Figure 3 Examples of protease expression in breast cancer from transgenic mice and humans. Expression of MMP-13 during early invasion in mouse C3(1)SV40-T breast carcinoma (a) and in human ductal carcinoma in situ (DCIS) (b). MMP-13 is focally expressed in periductal fibroblast-like cells (arrows in a, a', and b') in areas with early cancer cell invasion (inv) and is not expressed in adjacent noninvasive areas with in situ carcinoma (CIS). Expression of MMP-13 in invasive MMTVPymT carcinoma (c) and in human invasive ductal carcinoma (IDC) of the breast (d). Focal expression of MMP-13 is seen in fibroblast-like cells located in the stroma surrounding invasive cancer cells in both mouse and human breast cancers (arrows in c and d). Expression of PAI-1 in invasive MMTVPymT carcinoma (e) and in human IDC of the breast (f). The expression of PAI- 1 is seen in fibroblast-like cells located in the stroma surrounding invasive cancer cells in both the mouse and human breast cancers (arrows in e and f). All panels are in situ hybridization using $35 \mathrm{~S}-$ labeled probes. Panels a, c-f are counterstained with haematoxylin and eosin, whereas $\mathbf{b}$ is combined with pan-cytokeratin immunohistochemistry and (b') with CK14 immunohistochemistry for myoepithelial cells [35]. Bars: a,c, $200 \mu \mathrm{m} ; \mathbf{b}, 100 \mu \mathrm{m}$; d-f, $150 \mu \mathrm{m}$.
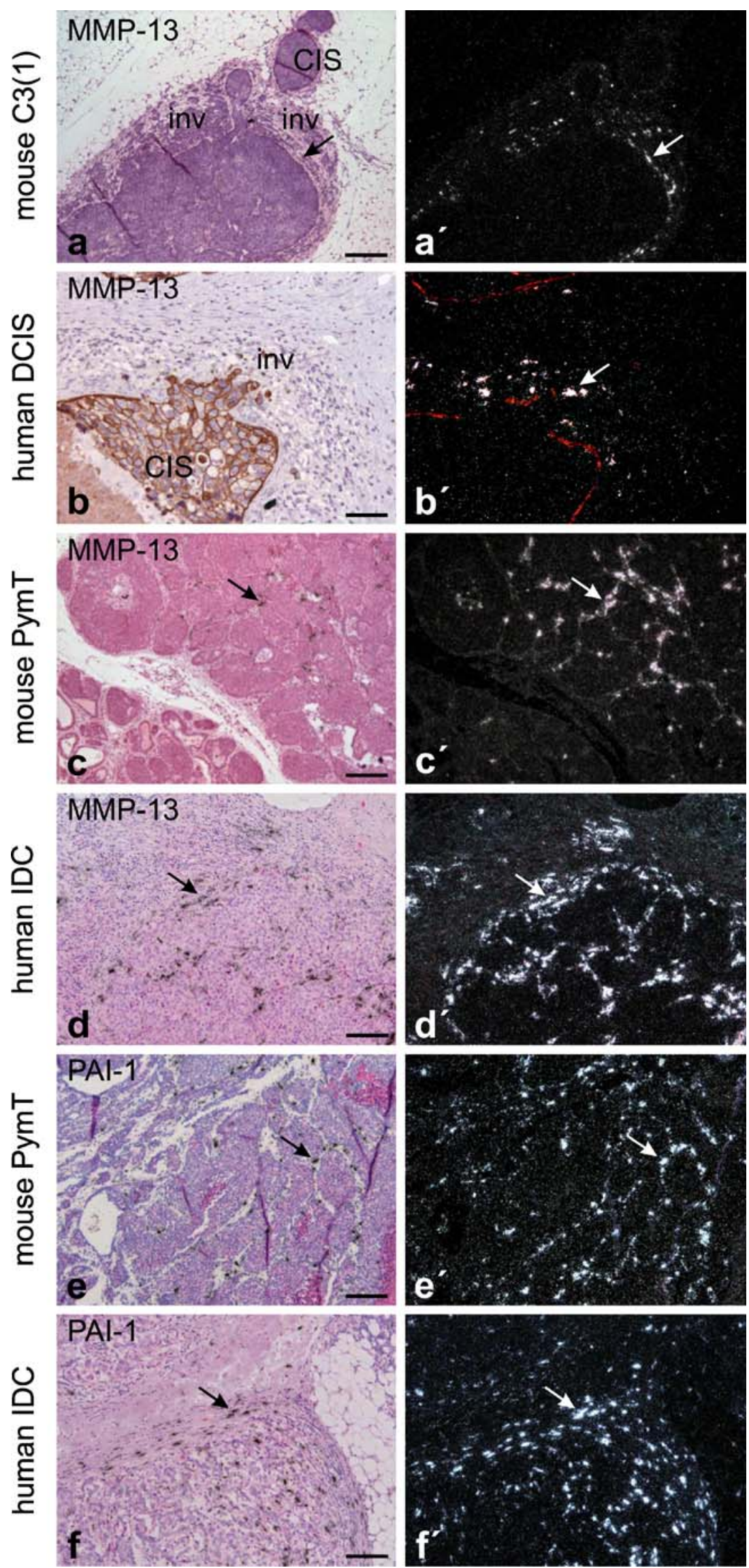
show a change in mammary apoptosis $[16,57]$. The fact that the PA system and the MMPs are required for the controlled tissue remodeling of the involuting mammary gland, suggests that it is the inherent proteolytic repertoire of the mammary gland that is reactivated in breast cancers.

\section{Proteases in Hyperplasia and Carcinogenesis}

The earliest stages of mammary carcinogenesis including the initial genetic alterations in the epithelial cells were previously considered to be independent of the surrounding stroma and extracellular proteolysis. It now seems that the structural integrity of the stroma is an essential factor in preventing carcinogenesis [60]. In fact, disruption of the ECM and cellular microenvironment caused by overexpression of MMPs-3, -7 or -14 in the mammary gland is sufficient to initiate mammary epithelial hyperplasia [29, 61-63]. Transgenic mice overexpressing MMP-3 or MMP14 even develop tumors in the absence of a transgenesupplied oncogene, and a fraction of the tumors undergo malignant transformation [62,63]. Similar transgenic overexpression of Plg activators has not been reported for the mammary gland, but a K14-uPA/uPAR double transgene elicits extensive skin hyperplasia [64]. The MMP transgenes all direct MMP expression to the mammary epithelium, using either MMTV or WAP promoters. Only MMP-7 is expressed by normal mammary epithelium [65], while MMPs-3 and -14 are expressed by the mammary stroma during development and in the mature gland $[46,61]$. Thus, tumor growth and malignancy have only been reported in cases where extracellular proteases were expressed by cells that would not normally produce them. Nevertheless, ectopically expressed proteases act as independent tumor promoters, presumably by compromising the growthinhibitory role of the stroma, and eventually lead to genetic instability as if they were conventional oncogenes.

In light of the independent tumorigenic ability of some MMP transgenes, it is not surprising that tumor onset in transgenic breast cancer models is promoted by increased MMP activity and delayed by decreased MMP activity in some studies (Table 1). Tumor onset is thus promoted by MMP-7 overexpression in the MMTV-neu model [29] and delayed by MMP-11 deficiency in the MMTV-ras model [30] or by TIMP-2 overexpression in the MMTV-Wnt1 model [32]. Similarly, the incidence of DMBA-induced mammary tumors is reduced in MMP-11-deficient [66] and in TIMP-1-overexpressing mice [34]. The results of two studies were inconsistent with the general finding: MMP-3 overexpression resulted in reduced rather than increased tumor incidence in the DMBA model [33], and MMP-9 deficiency led to increased tumorigenesis in the MMTVneu model [67]. This suggests that some MMPs may have a protective function in mammary tumorigenesis, similar to the protective role of MMP-8 in chemical carcinogenesis of the skin [68].

In contrast to the documented influence of some of the MMPs on tumor initiation, the PA system (including genetic deficiency in Plg [44], uPA [31], PAI-1 [45], or uPAR [unpublished data]) does not affect tumor onset in the MMTV-PymT model. Neither does TIMP-1 overexpression [34] or genetic deficiencies of MMPs-2, -7, -9 (Fingleton and Matrisian, personal communication) or MMP-13 (unpublished data) in the MMTV-PymT model. At present it is difficult to determine whether these differences reflect the nature of the different proteases or perhaps that the very early tumor onset, which takes place during puberty in the MMTV-PymT model, is less sensitive to the proteolytic environment.

Proteases in Tumor Growth and Vascularization

Mammary hyperplasias and CIS lesions are generally supplied with oxygen and nutrients by the pre-existing vasculature of the mammary gland. Tumor expansion beyond a certain stage requires the formation of new blood vessels. Angiogenesis, the sprouting of new vessels from existing vasculature, depends on proteolytic dissection of the endothelial basement membrane and other ECM components. Endothelial cells penetrate a newly deposited fibrin-rich matrix and use it as a temporary scaffold for vessel structure [69]. Accordingly, the fibrinolytic capacity of the PA system is crucial for vascularization in certain experimental settings, and PAI-1 may play a dual role as a protease inhibitor and cell migration mediator [3]. In tumors from breast cancer patients, endothelial cells are a considerable source of UPA, PAI-1 and uPAR suggesting a possible role in vascularization $[47,48,52]$. This has not been experimentally confirmed in transgenic tumors thus far (Table 1). In the MMTV-PymT model, tumors grow equally fast in the genetic absence or presence of Plg [44], uPA [31], PAI-1 [45] or uPAR (unpublished data), indicating that vascularization is not rate limiting for tumor growth in these cases. It is likely that functional redundancy with other proteolytic components compensates for the absence of a single component in the intact tumor. Even in PAI-1-deficient tumors, vascular density was not significantly different from wild type tumors [45]. It is also possible that vascularization of spontaneous tumors can be partially accomplished by endothelial precursor cells in a process termed vasculogenesis that may be independent of proteases or depend on a different subset of proteases [11].

Deficiency of MMP-9 reduces tumor growth in transgenic models of skin or $\beta$-cell islet tumors, most likely due to a requirement for MMP-9 to release vascular endothelial growth factor (VEGF) from ECM deposits in order to activate the angiogenic response $[70,71]$. In human breast 
tumors MMP-9 is expressed by a subset of inflammatory cells and vascular pericytes, which could suggest a similar role of MMP-9 in breast cancer vascularization [72]. However, the evidence is less clear in transgenic breast cancer models (Table 1). Final tumor size in MMTV-PymTtransgenic mice is not significantly affected by single gene deficiencies of MMPs-2, -7, -9 (Fingleton and Matrisian, personal communication), or MMP-13 (unpublished data). Deficiency of a single MMP may be compensated by the presence of other MMPs. In contrast, simultaneous inhibition of a number of MMPs through a liver-specific TIMP-1 transgene significantly reduced final tumor size (by $42 \%$ ) in MMTV-PymT mice [34]. Transgenic overexpression of TIMP-2 also caused a significant reduction in tumor growth rate and reduced the mean blood vessel size in MMTVWnt1 mammary tumors, providing direct evidence for an effect on vascularization [32]. MMP-11 may be important at this stage, since MMP-11-deficient mice develop significantly smaller tumors in the DMBA [66] and MMTV-ras [30] models. Surprisingly, a broad spectrum MMP inhibitor (galardin) only resulted in a $50 \%$ reduction in final tumor size in the MMTV-PymT model (unpublished data). It is possible that some MMPs promote while others inhibit tumor growth and vascularization, and the net effect of inhibiting a whole range of MMPs is rather limited. A protective role against tumor growth and vascularization has been observed in non-mammary models for MMP-3 [73] and MMP-19 [74].

\section{Proteases in Cancer Metastasis}

In order to successfully form metastases, cancer cells must enter the lymphatic system or the bloodstream, survive in circulation and arrest in the vasculature, extravasate and finally be able to proliferate in the new tissue. There are several metastasizing transgenic models, but the majority of models metastasize rather infrequently and only when the primary tumors are quite large. In addition to the MMTVPymT [28] and MMTV-neu [25] models, very few other breast cancer models metastasize sufficiently to allow rigorous quantification (reviewed in [75]). Metastasis can be greatly accelerated by combining e.g. an MMTV-neu model with a second mammary-specific transgene for VEGF or transforming growth factor- $\beta 1$ (TGF $\beta 1$ ) [75-77], but these models require more elaborate breeding. Proteases are intimately associated with metastasis. A classic example is the osteolytic bone metastases that are so frequent in breast cancer patients. Breast cancer cells and the resident osteoclasts stimulate each other in a feed-back activation loop. Cancer cells stimulate MMP-dependent degradation of the collagen type I rich bone matrix by osteoclasts [78, 79]. As a consequence of bone lysis, latent growth factors are released from their deposits within the bone ECM, and are available to stimulate further cancer cell proliferation. Unfortunately, transgenic models generally metastasize to the lungs and in this way the models do not exactly mimic the organ preference of metastatic breast cancer in humans.

The PA system plays a unique role in metastasis at least in the MMTV-PymT model that metastasizes to the lungs [28] and lymph nodes [31] (Table 1). uPA [31], PAI-1 [45], and UPAR (unpublished data) are all expressed both in the primary tumor and in the lung metastases. Metastasis is significantly reduced in both Plg-deficient and uPA-deficient mice, while these gene deficiencies have no significant effect on the primary MMTV-PymT tumors [31, 44]. Absence of the specific UPA inhibitor PAI-1 has a slight metastasispromoting effect, but the difference is not significant perhaps due to the presence of alternative UPA inhibitors [45]. Deficiency of UPAR does not significantly affect metastasis in the inbred FVB strain (unpublished data).

Plg and uPA may promote metastasis due to their fibrinolytic ability. Fibrin-deficient mice have not been studied in a transgenic model, but they are less susceptible to spontaneous metastasis from transplanted tumors [80] and lung colonization by tail vein-injected cells [81], suggesting that fibrin is important for sustained adhesion of circulating cancer cells in the target organ. Thus, metastasis may depend on an intact and balanced system of fibrin formation and fibrinolysis. Alternatively, Plg and uPA may promote metastasis by releasing growth factors from the ECM. Overexpression of relevant ECM-sequestered growth factors promotes breast cancer progression and metastasis in transgenic models $[76,77,82,83]$. These growth factors include the possible plasmin substrates VEGF, TGF $\beta$, and FGF (fibroblast growth factor), as well as the possible uPA substrate HGF (hepatocyte growth factor).

There is also considerable evidence linking the MMPs to invasion and metastasis (reviewed in [10, 84]). In MMTVPymT mice treated with the broad spectrum MMP inhibitor galardin, the average lung metastasis volume is reduced by approximately $99 \%$, in the context of primary tumors that are only reduced by half (unpublished data). Metastasis incidence is also reduced in MMTV-PymT mice that overexpress TIMP-1 through a liver-specific transgene, but the reduction is less pronounced and is absent with a mammary gland-specific TIMP-1 transgene [34]. It will take a considerable effort to define which MMPs are responsible for the metastasis reduction observed with these inhibitors. MMP-9 deficiency results in reduced metastasis in the MMTV-PymT model, although this phenotype was mouse strain dependent (Fingleton and Matrisian, personal communication). Deficiency of MMP-2, which is abundantly expressed in the stroma of MMTVPymT tumors [43], also results in reduced metastasis in the same model (Fingleton and Matrisian, personal communication). MMPs-2 and -9 have previously been associated 
with invasion and metastasis in a number of studies [84]. In contrast, there is no effect on metastasis in MMTV-PymT mice that are deficient in either MMP-7 (Fingleton and Matrisian, personal communication) or MMP-13 (unpublished data). Similarly, overexpression of MMP-7 in mammary glands has no effect on lung metastasis in the MMTV-neu model [29].

MMP-11 may play an unexpected role in actually preventing metastasis. In the MMTV-ras model, MMP-11 deficiency results in a higher number of metastases despite a lower number and volume of primary tumors [30]. Apparently, the transition to invasive carcinoma is greatly accelerated in the MMP-11 null mice, indicative of a protective function of MMP-11. A similar protective role against metastasis has been reported in non-mammary models for MMP-3 [73] and MMP-12 [85]. Thus, while the general MMP inhibitor galardin has a large inhibitory effect on metastasis, several single MMP knock-out studies report no effect or even the opposite effect on metastasis in breast cancer models. This demonstrates the potential of MMP inhibitors in preventing spontaneous metastasis but also underlines the necessity of evaluating a second generation of MMP inhibitors for clinical trials that are more specific than previous compounds. Transgenic models with a well-characterized involvement of MMPs in metastasis could be a useful tool in testing such compounds.

\section{Conclusion and Future Perspectives}

Transgenic breast cancer models are invaluable research tools because they recapitulate the entire process from the initial genetic events in normal cells to metastatic disease. Furthermore, the very similar expression patterns of extracellular proteases in human and mouse breast cancer samples suggest that transgenic mouse models are ideally suited to study the role of proteases in carcinogenesis and the progression to invasion and metastasis.

We have only begun to examine gene deficiencies and transgenic overexpression of the various PA and MMP components in transgenic models. The studies that have been performed so far suggest that no single MMP or PA system component is likely to be all-important for any stage in tumor progression. Practically all of the protease intervention studies report partial phenotypes such as delayed carcinogenesis, slower tumor growth or reduced metastasis, if they report any phenotype at all. The absence of any absolute phenotypes, such as prevention of metastasis, suggests that many of the proteases have mutually overlapping functions. The challenge for developing novel therapeutics in the future will be to identify those proteases that can be targeted simultaneously to obtain a synergistic tumor-suppressive effect.
Another area that has so far only been thoroughly examined in one or two transgenic models is the expression patterns of proteases. Using protease array data, it may be possible to draw some more detailed parallels between individual mouse models and certain histopathological subtypes of human breast cancers. It is very possible that the collective of transgenic breast cancer models available, rather than any single transgenic, will be needed to adequately model the heterogenous human disease. Another open question is whether certain proteases or inhibitors are up- or downregulated in response to certain gene deficiencies. This may provide vital information on functional overlap between individual proteases.

Transgenic breast cancer mice may prove to be very reliable models not only for basic research but also for testing experimental anti-proteolytic therapeutics, due to the high degree of similarity with human breast cancer. However, the transgenic models also present some significant challenges. A key issue is that the experimental drug has to cross-react with the mouse version of the protease. Therefore, it may be necessary in some cases to develop two drugs in parallel, one for each species. Due to the extracellular nature of the PA and MMP systems, these represent excellent targets for therapeutic monoclonal antibodies. An elegant method for targeting extracellular proteases in transgenic mice is the development of monoclonal anti-mouse antibodies by immunizing protease-deficient mice with the target protease. In conclusion, transgenic breast cancer models will further the identification of extracellular proteases critical to cancer invasion and metastasis, and aid the development of new agents against the spread of cancer.

Acknowledgments We are grateful to Drs. Barbara Fingleton and Lynn Matrisian for sharing unpublished results, and to Dr. Fritz Rank for assistance with histopathological evaluation of tumor samples. The assistance of Mr. John Post in creating the artwork is greatly appreciated. This work was supported by grants from the Danish Cancer Research Foundation, the Copenhagen Hospital Corporation, the "Grosserer Alfred Nielsen og hustrus" foundation, the European Commission grant LSHC-CT-2003-503297, and the European Union research training grant for mammary gland biology RTN-2002-00246.

\section{References}

1. Green KA, Lund LR. ECM degrading proteases and tissue remodelling in the mammary gland. BioEssays 2005;27:894-903.

2. Johnsen M, Lund LR, Rømer J, Almholt K, Danø K. Cancer invasion and tissue remodeling: common themes in proteolytic matrix degradation. Curr Opin Cell Biol 1998;10:667-71.

3. Andreasen PA, Egelund R, Petersen HH. The plasminogen activation system in tumor growth, invasion, and metastasis. Cell Mol Life Sci 2000;57:25-40.

4. Bass R, Ellis V. Cellular mechanisms regulating non-haemostatic plasmin generation. Biochem Soc Trans 2002;30:189-94. 
5. Lund LR, Bjørn SF, Sternlicht MD, Nielsen BS, Solberg H, Usher $\mathrm{PA}$, et al. Lactational competence and involution of the mouse mammary gland require plasminogen. Development 2000; 127:4481-92.

6. Rømer J, Bugge TH, Pyke C, Lund LR, Flick MJ, Degen JL, et al. Impaired wound healing in mice with a disrupted plasminogen gene. Nat Med 1996;2:287-92.

7. Solberg H, Rinkenberger J, Danø K, Werb Z, Lund LR. A functional overlap of plasminogen and MMPs regulates vascularization during placental development. Development 2003; 130:4439-50.

8. Lund LR, Green KA, Stoop AA, Ploug M, Almholt K, Lilla J, et al. Plasminogen activation independent of UPA and tPA maintains wound healing in gene-deficient mice. EMBO J 2006;25:2686-97.

9. Selvarajan S, Lund LR, Takeuchi T, Craik CS, Werb Z. A plasma kallikrein-dependent plasminogen cascade required for adipocyte differentiation. Nat Cell Biol 2001;3:267-75.

10. Egeblad M, Werb Z. New functions for the matrix metalloproteinases in cancer progression. Nat Rev Cancer 2002;2:161-74.

11. Jodele S, Blavier L, Yoon JM, DeClerck YA. Modifying the soil to affect the seed: role of stromal-derived matrix metalloproteinases in cancer progression. Cancer Metastasis Rev 2006;25:35-43.

12. Fata JE, Leco KJ, Moorehead RA, Martin DC, Khokha R. TIMP-1 is important for epithelial proliferation and branching morphogenesis during mouse mammary development. Dev Biol 1999;211:238-54.

13. Wiseman BS, Sternlicht MD, Lund LR, Alexander CM, Mott J, Bissell MJ, et al. Site-specific inductive and inhibitory activities of MMP-2 and MMP-3 orchestrate mammary gland branching morphogenesis. J Cell Biol 2003;162:1123-33.

14. Stickens D, Behonick DJ, Ortega N, Heyer B, Hartenstein B, Yu Y, et al. Altered endochondral bone development in matrix metalloproteinase 13-deficient mice. Development 2004;131:5883-95.

15. Lund LR, Rømer J, Bugge TH, Nielsen BS, Frandsen TL, Degen $\mathrm{JL}$, et al. Functional overlap between two classes of matrixdegrading proteases in wound healing. EMBO J 1999;18:4645-56.

16. Alexander CM, Selvarajan S, Mudgett J, Werb Z. Stromelysin-1 regulates adipogenesis during mammary gland involution. J Cell Biol 2001;152:693-703.

17. Cardiff RD, Wellings SR. The comparative pathology of human and mouse mammary glands. J Mammary Gland Biol Neoplasia 1999;4:105-22.

18. Hovey RC, McFadden TB, Akers RM. Regulation of mammary gland growth and morphogenesis by the mammary fat pad: a species comparison. J Mammary Gland Biol Neoplasia 1999;4:53-68.

19. Metcalfe AD, Gilmore A, Klinowska T, Oliver J, Valentijn AJ, Brown R, et al. Developmental regulation of Bcl-2 family protein expression in the involuting mammary gland. J Cell Sci 1999;112:1771-83.

20. Lin EY, Jones JG, Li P, Zhu L, Whitney KD, Muller WJ, et al. Progression to malignancy in the polyoma middle $\mathrm{T}$ oncoprotein mouse breast cancer model provides a reliable model for human diseases. Am J Pathol 2003;163:2113-26.

21. Ploug M, Østergaard S, Gårdsvoll H, Kovalski K, Holst-Hansen C, Holm A, et al. Peptide-derived antagonists of the urokinase receptor. Affinity maturation by combinatorial chemistry, identification of functional epitopes, and inhibitory effect on cancer cell intravasation. Biochemistry 2001;40:12157-68.

22. Almholt K, Johnsen M. Stromal cell involvement in cancer. Recent Results Cancer Res 2003;162:31-42.

23. Shen Q, Brown PH. Transgenic mouse models for the prevention of breast cancer. Mutat Res 2005;576:93-110.

24. Cardiff RD, Anver MR, Gusterson BA, Hennighausen L, Jensen RA, Merino MJ, et al. The mammary pathology of genetically engineered mice: the consensus report and recommendations from the Annapolis meeting. Oncogene 2000;19:968-88.
25. Guy CT, Webster MA, Schaller M, Parsons TJ, Cardiff RD, Muller WJ. Expression of the neu protooncogene in the mammary epithelium of transgenic mice induces metastatic disease. Proc Natl Acad Sci U S A 1992;89:10578-82.

26. Sinn E, Muller W, Pattengale P, Tepler I, Wallace R, Leder P. Coexpression of MMTV/v-Ha-ras and MMTV/c-myc genes in transgenic mice: synergistic action of oncogenes in vivo. Cell 1987;49:465-75.

27. Tsukamoto AS, Grosschedl R, Guzman RC, Parslow T, Varmus HE. Expression of the int-1 gene in transgenic mice is associated with mammary gland hyperplasia and adenocarcinomas in male and female mice. Cell 1988;55:619-25.

28. Guy CT, Cardiff RD, Muller WJ. Induction of mammary tumors by expression of polyomavirus middle $\mathrm{T}$ oncogene: a transgenic mouse model for metastatic disease. Mol Cell Biol 1992;12:954-61.

29. Rudolph-Owen LA, Chan R, Muller WJ, Matrisian LM. The matrix metalloproteinase matrilysin influences early-stage mammary tumorigenesis. Cancer Res 1998;58:5500-6.

30. Andarawewa KL, Boulay A, Masson R, Mathelin C, Stoll I, Tomasetto C, et al. Dual stromelysin-3 function during natural mouse mammary tumor virus-ras tumor progression. Cancer Res 2003;63:5844-9.

31. Almholt K, Lund LR, Rygaard J, Nielsen BS, Danø K, Rømer J, et al. Reduced metastasis of transgenic mammary cancer in urokinase-deficient mice. Int J Cancer 2005;113:525-32.

32. Blavier L, Lazaryev A, Dorey F, Shackleford GM, DeClerck YA. Matrix metalloproteinases play an active role in Wnt1-induced mammary tumorigenesis. Cancer Res 2006;66:2691-9.

33. Witty JP, Lempka T, Coffey RJ, Jr., Matrisian LM. Decreased tumor formation in 7,12-dimethylbenzanthracene-treated stromelysin-1 transgenic mice is associated with alterations in mammary epithelial cell apoptosis. Cancer Res 1995;55:1401-6.

34. Yamazaki M, Akahane T, Buck T, Yoshiji H, Gomez DE, Schoeffner DJ, et al. Long-term exposure to elevated levels of circulating TIMP1 but not mammary TIMP-1 suppresses growth of mammary carcinomas in transgenic mice. Carcinogenesis 2004;25:1735-46.

35. Nielsen BS, Rank F, López JM, Balbin M, Vizoso F, Lund LR, et al. Collagenase-3 expression in breast myofibroblasts as a molecular marker of transition of ductal carcinoma in situ lesions to invasive ductal carcinomas. Cancer Res 2001;61:7091-100.

36. Nielsen BS, Rank F, Illemann M, Lund LR, Danø K. Stromal cells associated with early invasive foci in human mammary ductal carcinoma in situ co-express urokinase and urokinase receptor. Int $\mathrm{J}$ Cancer (in press).

37. Cardiff RD, Moghanaki D, Jensen RA. Genetically engineered mouse models of mammary intraepithelial neoplasia. J Mammary Gland Biol Neoplasia 2000;5:421-37.

38. Green JE, Shibata MA, Yoshidome K, Liu ML, Jorcyk C, Anver MR, et al. The C3(1)/SV40 T-antigen transgenic mouse model of mammary cancer: ductal epithelial cell targeting with multistage progression to carcinoma. Oncogene 2000;19:1020-7.

39. Schulze-Garg C, Löhler J, Gocht A, Deppert W. A transgenic mouse model for the ductal carcinoma in situ (DCIS) of the mammary gland. Oncogene 2000;19:1028-37.

40. Talhouk RS, Bissell MJ, Werb Z. Coordinated expression of extracellular matrix-degrading proteinases and their inhibitors regulates mammary epithelial function during involution. J CellBiol 1992;118:1271-82.

41. Lefebvre O, Wolf C, Limacher JM, Hutin P, Wendling C, LeMeur $\mathrm{M}$, et al. The breast cancer-associated stromelysin-3 gene is expressed during mouse mammary gland apoptosis. J Cell Biol 1992;119:997-1002.

42. Lund LR, Rømer J, Thomasset N, Solberg H, Pyke C, Bissell MJ, et al. Two distinct phases of apoptosis in mammary gland involution: proteinase-independent and -dependent pathways. Development 1996;122:181-93. 
43. Pedersen TX, Pennington CJ, Almholt K, Christensen IJ, Nielsen BS, Edwards DR, et al. Protease mRNAs are predominantly expressed in the stromal areas of microdissected mouse breast carcinomas. Carcinogenesis 2005;26:1233-40.

44. Bugge TH, Lund LR, Kombrinck KK, Nielsen BS, Holmbäck K, Drew AF, et al. Reduced metastasis of Polyoma virus middle $\mathrm{T}$ antigen-induced mammary cancer in plasminogen-deficient mice. Oncogene 1998;16:3097-104.

45. Almholt K, Nielsen BS, Frandsen TL, Brünner N, Danø K, Johnsen M. Metastasis of transgenic breast cancer in plasminogenactivator inhibitor-1 gene-deficient mice. Oncogene 2003;22:4389-97.

46. Szabova L, Yamada SS, Birkedal-Hansen H, Holmbeck K. Expression pattern of four membrane-type matrix metalloproteinases in the normal and diseased mouse mammary gland. J Cell Physiol 2005;205:123-32.

47. Nielsen BS, Sehested M, Duun S, Rank F, Timshel S, Rygaard J, et al. Urokinase plasminogen activator is localized in stromal cells in ductal breast cancer. Lab Invest 2001;81:1485-502.

48. Offersen BV, Nielsen BS, Høyer-Hansen G, Rank F, HamiltonDutoit $\mathrm{S}$, Overgaard $\mathrm{J}$, et al. The myofibroblast is the predominant plasminogen activator inhibitor-1 expressing cell type in human breast carcinomas. Am J Pathol 2003;163:1887-99.

49. Wolf C, Rouyer N, Lutz Y, Adida C, Loriot M, Bellocq J-P, et al. Stromelysin 3 belongs to a subgroup of proteinases expressed in breast carcinoma fibroblastic cells and possibly implicated in tumor progression. Proc Natl Acad Sci USA 1993;90:1843-7.

50. Nakopoulou L, Giannopoulou I, Gakiopoulou H, Liapis H, Tzonou A, Davaris PS. Matrix metalloproteinase-1 and -3 in breast cancer: correlation with progesterone receptors and other clinicopathologic features. Hum Pathol 1999;30:436-42.

51. Okada A, Bellocq J-P, Rouyer N, Chenard M-P, Rio M-C, Chambon $\mathrm{P}$, et al. Membrane-type matrix metalloproteinase (MT-MMP) gene is expressed in stromal cells of human colon, breast, and head and neck carcinomas. Proc Natl Acad Sci U S A 1995;92:2730-4.

52. Pyke C, Græm N, Ralfkiær E, Rønne E, Høyer-Hansen G, Brünner $\mathrm{N}$, et al. Receptor for urokinase is present in tumorassociated macrophages in ductal breast carcinoma. Cancer Res 1993;53:1911-5.

53. Sappino AP, Skalli O, Jackson B, Schurch W, Gabbiani G. Smooth-muscle differentiation in stromal cells of malignant and non-malignant breast tissues. Int J Cancer 1988;41:707-12.

54. Brummer O, Athar S, Riethdorf L, Löning T, Herbst H. Matrixmetalloproteinases 1,2 , and 3 and their tissue inhibitors 1 and 2 in benign and malignant breast lesions: an in situ hybridization study. Virchows Arch 1999;435:566-73.

55. Green KA, Nielsen BS, Castellino FJ, Rømer J, Lund LR. Lack of plasminogen leads to milk stasis and premature mammary gland involution during lactation. Dev Biol 2006;299:164-75.

56. Fata JE, Leco KJ, Voura EB, Yu HY, Waterhouse P, Murphy G, et al. Accelerated apoptosis in the Timp-3-deficient mammary gland. J Clin Invest 2001;108:831-41.

57. Alexander CM, Howard EW, Bissell MJ, Werb Z. Rescue of mammary epithelial cell apoptosis and entactin degradation by a tissue inhibitor of metalloproteinases-1 transgene. J Cell Biol 1996;135:1669-77.

58. Li F, Strange R, Friis RR, Djonov V, Altermatt HJ, Saurer S, et al. Expression of stromelysin-1 and TIMP-1 in the involuting mammary gland and in early invasive tumors of the mouse. Int $\mathbf{J}$ Cancer 1994;59:560-8.

59. Sympson CJ, Talhouk RS, Alexander CM, Chin JR, Clift SM, Bissell MJ, et al. Targeted expression of stromelysin-1 in mammary gland provides evidence for a role of proteinases in branching morphogenesis and the requirement for an intact basement membrane for tissue-specific gene expression. J Cell Biol 1994;125:681-93.
60. Radisky DC, Bissell MJ. Matrix metalloproteinase-induced genomic instability. Curr Opin Genet Dev 2006;16:45-50.

61. Witty JP, Wright JH, Matrisian LM. Matrix metalloproteinases are expressed during ductal and alveolar mammary morphogenesis, and misregulation of stromelysin-1 in transgenic mice induces unscheduled alveolar development. Mol Biol Cell 1995;6:1287-303.

62. Sternlicht MD, Lochter A, Sympson CJ, Huey B, Rougier J-P, Gray JW, et al. The stromal proteinase MMP3/stromelysin-1 promotes mammary carcinogenesis. Cell 1999;98:137-46.

63. Ha HY, Moon HB, Nam MS, Lee JW, Ryoo ZY, Lee TH, et al. Overexpression of membrane-type matrix metalloproteinase-1 gene induces mammary gland abnormalities and adenocarcinoma in transgenic mice. Cancer Res 2001;61:984-90.

64. Bolon I, Zhou H-M, Charron Y, Wohlwend A, Vassalli J-D. Plasminogen mediates the pathological effects of urokinase-type plasminogen activator overexpression. Am J Pathol 2004;164:2299 304.

65. Saarialho-Kere UK, Crouch EC, Parks WC. Matrix metalloproteinase matrilysin is constitutively expressed in adult human exocrine epithelium. J Invest Dermatol 1995;105:190-6.

66. Masson R, Lefebvre O, Noël A, El Fahime M, Chenard M-P, Wendling $\mathrm{C}$, et al. In vivo evidence that the stromelysin-3 metalloproteinase contributes in a paracrine manner to epithelial cell malignancy. J Cell Biol 1998;140:1535-41.

67. Kenny PA, Rizki A. 42nd Annual Meeting of the American Society for Cell Biology, San Francisco, California, USA, 14-18 December 2002. Breast Cancer Res 2003;5:147-53.

68. Balbín M, Fueyo A, Tester AM, Pendás AM, Pitiot AS, Astudillo A, et al. Loss of collagenase-2 confers increased skin tumor susceptibility to male mice. Nat Genet 2003;35:252-7.

69. Dvorak HF, Brown LF, Detmar M, Dvorak AM. Vascular permeability factor/vascular endothelial growth factor, microvascular hyperpermeability, and angiogenesis. Am J Pathol 1995;146:1029-39.

70. Coussens LM, Tinkle CL, Hanahan D, Werb Z. MMP-9 supplied by bone marrow-derived cells contributes to skin carcinogenesis. Cell 2000;103:481-90.

71. Bergers G, Brekken R, McMahon G, Vu TH, Itoh T, Tamaki K, et al. Matrix metalloproteinase-9 triggers the angiogenic switch during carcinogenesis. Nat Cell Biol 2000;2:737-44.

72. Nielsen BS, Sehested M, Kjeldsen L, Borregaard N, Rygaard J, Danø K. Expression of matrix metalloprotease-9 in vascular pericytes in human breast cancer. Lab Invest 1997;77:345-55.

73. McCawley LJ, Crawford HC, King LE, Jr., Mudgett J, Matrisian LM. A protective role for matrix metalloproteinase-3 in squamous cell carcinoma. Cancer Res 2004;64:6965-72.

74. Jost M, Folgueras AR, Frérart F, Pendas AM, Blacher S, Houard $\mathrm{X}$, et al. Earlier onset of tumoral angiogenesis in matrix metalloproteinase-19-deficient mice. Cancer Res 2006;66:5234-41.

75. Fantozzi A, Christofori G. Mouse models of breast cancer metastasis. Breast Cancer Res 2006;8:212-22.

76. Muraoka RS, Koh Y, Roebuck LR, Sanders ME, Brantley-Sieders D, Gorska AE, et al. Increased malignancy of Neu-induced mammary tumors overexpressing active transforming growth factor $\beta 1$. Mol Cell Biol 2003;23:8691-703.

77. Oshima RG, Lesperance J, Munoz V, Hebbard L, Ranscht B, Sharan N, et al. Angiogenic acceleration of Neu induced mammary tumor progression and metastasis. Cancer Res 2004;64:169-79.

78. Winding B, NicAmhlaoibh R, Misander H, Høegh-Andersen P, Andersen TL, Holst-Hansen C, et al. Synthetic matrix metalloproteinase inhibitors inhibit growth of established breast cancer osteolytic lesions and prolong survival in mice. Clin Cancer Res 2002;8:1932-9.

79. Yoneda T, Hiraga T. Crosstalk between cancer cells and bone microenvironment in bone metastasis. Biochem Biophys Res Commun 2005;328:679-87. 
80. Palumbo JS, Potter JM, Kaplan LS, Talmage K, Jackson DG, Degen JL. Spontaneous hematogenous and lymphatic metastasis, but not primary tumor growth or angiogenesis, is diminished in fibrinogen-deficient mice. Cancer Res 2002;62:6966-72.

81. Palumbo JS, Kombrinck KW, Drew AF, Grimes TS, Kiser JH, Degen $\mathrm{JL}$, et al. Fibrinogen is an important determinant of the metastatic potential of circulating tumor cells. Blood 2000;96:3302-9.

82. Kwan H, Pecenka V, Tsukamoto A, Parslow TG, Guzman R, Lin $\mathrm{TP}$, et al. Transgenes expressing the Wnt- 1 and int- 2 protooncogenes cooperate during mammary carcinogenesis in doubly transgenic mice. Mol Cell Biol 1992;12:147-54.

83. Takayama H, LaRochelle WJ, Sharp R, Otsuka T, Kriebel P, Anver $\mathrm{M}$, et al. Diverse tumorigenesis associated with aberrant development in mice overexpressing hepatocyte growth factor/scatter factor. Proc Natl Acad Sci USA 1997;94:701-6.

84. Deryugina EI, Quigley JP. Matrix metalloproteinases and tumor metastasis. Cancer Metastasis Rev 2006;25:9-34.

85. Houghton AM, Grisolano JL, Baumann ML, Kobayashi DK, Hautamaki RD, Nehring LC, et al. Macrophage elastase (matrix metalloproteinase-12) suppresses growth of lung metastases. Cancer Res 2006;66:6149-55.

86. Ling Q, Jacovina AT, Deora A, Febbraio M, Simantov R, Silverstein RL, et al. Annexin II regulates fibrin homeostasis and neoangiogenesis in vivo. J Clin Invest 2004;113:38-48.
87. Razzaq TM, Bass R, Vines DJ, Werner F, Whawell SA, Ellis $\mathrm{V}$. Functional regulation of tissue plasminogen activator on the surface of vascular smooth muscle cells by the type-II transmembrane protein p63 (CKAP4). J Biol Chem 2003;278:42679-85.

88. Oh J, Takahashi R, Kondo S, Mizoguchi A, Adachi E, Sasahara RM, et al. The membrane-anchored MMP inhibitor RECK is a key regulator of extracellular matrix integrity and angiogenesis. Cell 2001;107:789-800.

89. Heppner KJ, Matrisian LM, Jensen RA, Rodgers WH. Expression of most matrix metalloproteinase family members in breast cancer represents a tumor-induced host response. Am J Pathol 1996;149:273-82.

90. Matrisian LM. Cancer biology: extracellular proteinases in malignancy. Curr Biol 1999;9:R776-8.

91. Hulboy DL, Gautam S, Fingleton B, Matrisian LM. The influence of matrix metalloproteinase-7 on early mammary tumorigenesis in the multiple intestinal neoplasia mouse. Oncol Rep 2004;12:13-7.

92. Sacco MG, Soldati S, Indraccolo S, Cato EM, Cattaneo L, Scanziani E, et al. Combined antiestrogen, antiangiogenic and anti-invasion therapy inhibits primary and metastatic tumor growth in the MMTVneu model of breast cancer. Gene Ther 2003;10:1903-9. 